\title{
Paul Hansens Dagbog fra Løjt $1740-45$.
}

\section{Ved cand. theol. Hans Hejselbjerg Paulsen.}

Den Dagbog, vi i det følgende skal læse et Uddrag af, er fort af en Mand, som dengang var een af de forende paa Aabenraaegnen. Han ejede ikke alene een af de største Gaarde i Løjt Sogn, men sad ogsaa inde med betydelige Andele i Aabenraa-Skibene, ja ejede selv flere Sejlskibe og drev en ikke ubetydelig Handel. Det kan derfor være af nogen Interesse at læse et Udtog af en saadan Mands Dagbøger, da vi faar et lille Indblik $i$ en Tid, vi ellers kun kender saa lidt til.

Paul Hansen (1694-1780) fik Fødegaarden Jacobsgaard i Barsmark, Løjt Sogn 1727. Gaarden havde langt tilbage i Tiden været i Slægtens Eje.

I Barsmark var der 2 Knudsgaarde og to Jacobsgaarde, disse 4 hørte under Svavsted (Slesvig Bispestols Jord). I 1609 ejedes den nuvierende Jacobsgaard af Christine Hansen, Enke efter Hans Jacobsen.

1641 Nis Hansen (en Mark i Barsmark under Jacobsgaard hedder endnu efter ham Nis Hansens Dam).

1641-1658 Jes Jacobsen.

1658-1690 Paul Jessen. Hans Hustru hed Ingeborg Marquardsen, hun var fra Blosholm, hvor Familien M. - Løjt Sogns ældste boede. Det fortalles, at en Mand ved Navn Marquard fra Elsholm (i ældre Tid Ygylsjøholm) var den eneste, som overlevede Pesten - den sorte Død - 1349-1351 - Marquard, som i Folkemunde kaldtes "rød Marko paa Elsholnu, drog sammen med Munkene fra Løjt Kloster over til Barsø, hvor de levede i "Munkedal" (kaldes endnu saadan) i 3 Aar. Paa en Hoj ved Raahoel prædikede Munkene, og Højen kaldes endnu den Dag i Dag "Prærkhøju. Marquard af Elsholm fik Fruedag (d. e. 25. Marts) 1351 Elsholm til Len af Hertug Valdemar V. paa Sønderborg Slot.

Paul Jessen og Ingeborg Marquardsen havde to Sonner og to Detre

1) Hans Paulsen, født paa Jacobsgaard 1660,2$)$ Marquard Paulsen, han friede sig ind i den sydlige Fogedgaard i Barsmark. (Nu Nygaard).

Hans Paulsen paa Jacobsgaard (1660-1743)

havde Sønnerne Paul Hansen, Kaptajn og Ejer af Jacobsgaard Peter Paulsen til Østergaardsmølle.

Hans Paulsen, Kaptajn.

Paul Hansen (1694-1780) fik Jacobsgaard 1727. Han var gift med Mette Bossen fra Bossensgaard (Bossensgaard brændte 1914, den var een af Løjt Sogns wldste Gaarde, bl. a. fandtes der endnu i Kælderen flere Fangehuller). Hun var født i B. 1711. En Bro- 
der Hans Bossen var Skibsrheder og Storkøbmand i Holland. Hans Billede hænger endnu i Jacobsgaard. Paa Bossensgaard boede dengang en Enkefru Wright, Enke efter Skibsrheder Wright fra Porsgrund i Norge. Nogle af hendes Møbler fandtes endnu paa B. i 1914, men brændte sammen med Gaarden. Mettes Broder Matz Bossen havde Bossensgaard paa Paul Hansens Tid.

Det er Paul Hansen, som har ført den Dagbog, som nedenfor gengives i Udtog. Den begynder 1718. Han døde 1780. Hans Gravsten sidder indmuret i Jacobsgaird. Den er vel nok den smukkeste og mest kostbare Gravsten, vi har fra ældre Tid.

Af Paul Hansens Born fik Sønnen Hans Paulsen Jacobsgaard 1780, $(\uparrow 1805)$. Datteren Bodil, som omtales i Dagbogen, blev gift med Eschel Møller (Krag) paa Møllegaard. Manden døde allerede 1779, og hun arvede endvidere Jacobsgaard efter Broderen Hans Paulsen. Hun var desuden Arving til Bossensgaard; men hendes Morbroder Matz Bossen paa. B. syntes, at tre store Gaarde i Løjt Sogn blev for meget. IIan overdrog derfor Bossensgaard til en Plejedatter Ellen Skippers. Bodil gav siden Jacobsgaard til en Slrgtning Jep Matzen Krag. Hans Søns Sønnesøn er Hans Paulsen Krag, født paa Jacobsgaard 1875, som nu ejer den gamle Gaard.

For disse Oplysninger angaaente Jacobsgaard og dens Ejere, skylder jeg Rentier Hans 11. Toft, Barsmark, min hedste Tak.

Af Paul Hansens Dagbøger er kum en enkelt bevaret, og hvad jeg her gengiver fra Tiden inellem 1740 og 1745 , er kun et Udtog, idet en Mæugde Notater angaaende Handeler, Familieefterretninger, Arbejdet paa Gaarden osv. er udeladt. Jeg har kun medtaget det, som kan vere af Interesse i Dag i sproglig, personal- og kulturhistorisk Henseende. Nogle enkelte Priser paa Landbrugets Salgsvarer er taget med for at illustrere Datidens Indtagter $\mathrm{i}$ en nordslesvigsk Bondegaard.

Dagbogen er fort paa Tysk. Men det er jo tydeligt, at Mandens Sprogkundskaber - efter vore Begreber - er meget mangelfulde. At hans Modersmaal og daglige Talesprog er det sønderjydske Folkemaal, er indlysende, idet han dels bruger en Mængde sønderjydske Ord, hvor hans tyske Ordforraad svigter, dels er Sætningskonstruktionen helt igenmem dansk. Vi møder en hel Del Ord fra Folkesproget som f. Eks. Hild, Hjold, Bassel, Kost (Bryllup) gjære (sæette Hegn i Stand) Lyng, Dam, Sløef osv. Dernast findes en Del Ord, som vil vare en Tysker ganske uforstaaelige, t. Eks. He u f a g; zu t e ck e n (tække); wir klippen Schafe; to $\mathrm{Ha} \mathrm{u}$ bei der Kirche; kriegt H y r; ein Di e g machen; ich soll selbst de $\mathrm{N}$ a ch $\mathrm{g}$ r $\emptyset$ haben (Eftergrøden); en Sid Speck; der Schulmeister kam op de Kost; N. N. war bei unser K l o c k osv. Desuden ses det saa at sige 
i hver Sætning, at Sprogunderlaget er det danske. Forfatteren anvender f. Eks. meget hyppigt danske Præpositioner i tysk Oversættelse. "Bly til Kirken" bliver $\mathrm{i}$ hans Oversættelse til Blei z u der Kirche. "Bark til Tondring «-Bark zu T. Paa Sønderjydsk siger man jo f. Eks. "Jeg fik Penge ved min Broder". Paul H. skriver: "Ich kriegte Geld bei meinem Bruder". Af andre Eksempler "te Stajs" bliver til z u stadt; "beim Damm" i Stedet for am Teiche; Wir haben noch 14 Fuder Heu a u s (ude). Værre bliver det, naar den forkerte Oversættelsespræposition ganske forandrer Meningen. P. H. skriver saaleds et Sted "E. wurde f ür mich gestohlen«, hvor en Tysker begribeligvis vil mene, at en eller anden stjal til ham, og ikke aner, at Manden mener "Es wurde mir gestohlen«. Det er den Slags sproglige Snurrepiberier, man møder i de Grænselande, hvor Naturen -baade for og nu - saa hyppigt gaar over Optugtelsen. Af almindelige, mere tilgivelige Fejl, findes utallige. T. Eks. "in unsere Kirche" (hvor in efter Menningen skal styre Dativ), "bei unsre» skrives meget hyppigt (hvor bei skal styre Dativ). Verbet staar of te i Singularis, selvom Subjektet er Pluralis osv.

Dagbogen er ført $i$ en Tid, hvor det aarhundredegamle Fallesskab synger paa sit sidste Vers. Byhyrden i Barsmark møder endnu om Foraaret for at overtage Styret over sine Undersaatter, hvis Antal paa den fælles Græsmark beregnes efter de gamle Regler, hvor en Otting Jord danner Grundlaget for Beregningen. Paul Hansen er selv jævnlig beskæftiget ved Landmaaling rundt omkring paa Egnen, det er altsaa en Tid, hvor Landets Deling staar for Døren.

Gennem Dagbogen følger vi Sejlskibene paa deres Rejser. Forfatteren overantvorder Skib og Ladning til Guds Forsorg. naar Skibet staar ud af Fjorden, og takker Gud for Lykke og Held, naar det hjemvendte Skib har kastet Anker. Han begynder det nye Aar i Guds Navn, og takker for det gamle, som randt ud. Han fører Regnskab over, hvornaar han var tif Skrifte hos Præsten i Løjt, naar han og Hustruen var til Alters, saavel som naar han er bleven aareladt sidst. Manden selv skjuler sig for os bag alt det forretningsmæssige, som op- 
hobes; men vi faar et Indblik i Livet, som det førtes i en velhavende Mands Gaard i de Dage. Her møder vi de rige Studehandlere ude fra Marsken, fra Ejdersted og Stapelholm, Amtmand von Günderoth, hans Skriver og Sekretær. Her kommer nogle Gange om Aaret Orientalisten Pastor Fabricius, Sognepræsten i Løjt, som Sjælesørger, Ven og Raadgiver, ligeledes Diaconus i Lajt Canutus (eller Knud) Hybschmann. Ogsaa Præsten fra det træfattige Burkal Sogn, den lærde Andreas Ambders finder Vej til det frugtrige Barsmark for at hente en Tønde Abler mod at er]ægge en Rigsdaler som Betaling. Skibskaptajnerne kommer for at veksle Penge hos den velhavende Paul Hansen, Familie og Venner fra fjernt og nær aflægger jævnlig Besøg, vi træffer Læreren, som gaar paa Madning, nop de Kost«, som Paul Hansen kalder det. Her handles med stort og smaat, fra Skibsladninger til smaa Byttehandler, hvor det noget ubestemte "en Bog “ byttes mod en Kardus Tobak, eller en Gris for et Lispund Humle. I det hele taget modtages ofte Naturalier som Betaling i Stedet for rede Penge. Sælges der Smør eller Flæsk ved Skibene, faas ofte Klipfisk som Betaling. Uld betales med Hovarbejde, Karlens Løn bestaar foruden i Penge, i Linned til Skjorter og Tøj til Bukser; Bøgetræ betales dels med Penge, dels med "eine Rolle Tabak" o. s. fr.

Anno 1740.

Grott gieb uns ein fröhliches Neujahr!

Den 29. Dec. heuerten wir Chresten Schulmeister.

den 7. Januar köfft ich 3 Tonnen Gerste für 8 Sk. a ship.

den 10. Januar ist der kleine Heufach ledig, de weste Heufach und Hjold ist auch ledig.

den 18. J. war ich in Roten Krug mit einem Fuder Malz, krieg $91 / 4$ Sk. a ship.

den 19. J. liefert ich 155 Bund Heu to de Reiter, $\left.{ }^{1}\right)$ krieg auch Geld bei Lorenz Tobaksspinder für Vaters Kuh.

den 20. Jan. hatten wir Matz Kraghs Sløef und holten 3 Eichenblöcke in Bitterholt.

1) i Aabenraa. 
den 10. Febr. kam mein Bruder Hans von Hadersleben, wir kriegen ein jeder 100 Mark. ${ }^{1}$ )

den 2. März war ich zu Bassel bei Hans Auberk.

den 6. zu Bassel in Østergaardsinühle.

den 9. war ich zur Stadt u. kriegte Bescheid von Commerzienrath in Kopenhagen.

den 12. war Claus Baade von Eiderstedt hier und will Ochsen kaufen.

den '15. lieferte ich eine Rechnung auf de Ting. Jes Jessen bleibt schuldig 199 M. 1660 Mark stehen auf Zinsen.

den 24. verkauf ich einen zweijährigen Hingst an Ras Kjær in Walnitz für 32. W'ir haben noch 5 Fach Heu in grossen Heufach.

den 28. verkaufte ich 8 Ochsen zu Peter Schlachter a paar 28 Ril. 24 Sk.

9. April war ich in Klipleff zu Marked köfft en Quie. Wir pflügtenden Lükberg und den Rörsiig²) wir haben noch 4 Fach Heu.

den 29. jagen wir 5 stück Vieh aufs Grass. Der Hirte war hier u. schrieb das Vieh, Pferde u. Schweine. ${ }^{3}$ )

den 28. klippen wir unsere Schafe.

den 29. waren wir 6 Männer oder Sogneraadet mit dem Förster zur Holzbesichtigung.

dell 3. Maj kam H. F. Thomsen aus Stapelholm hier u. kaufte (; Ochsen a paar für 24 Rd. Nis Jager zu tecken auf de Westseite.

den 9. Maj war ich u. meine Frau Mett zum heiligen Abendmahl. Unsere Schafe kommen auf die Heide.")

den 12. Maj war ich und Hans Alsing in Apenrade mit 2 Fuder Heu zu Herr Major. Er kriegt 200 Bund, wiegt a Bund 12 Pd. für jedles Bund 2\% Sk. und Herr Erich ${ }^{5}$ ) kriegt 40 für $21 / 2$ Sk.

1) Andel i Skibe.

2) Et Siig er et Stykke lavtliggende Jord.

3) I Fiellesskabets Tid.

-) Ved Røde Kro eller $\varnothing$. Lagum.

s) Vistnok Diakonus i Aabenraa Frich Fabricius, Prast i Aabenraa $1728-1782$. 
den 21. segelt mein Bruder Hans Paulsen von Apenrade. Gott gieb ihm Glück u. Segen.

den 22. Maj jagen wir unsere Kühe aufs Gras, da ist nur wenig Gras, die Weitle ist nicht grün.

den 25. Maj kommt der Viehhändler H. F. Thomsen aus stappelholm mit unserem Gelde für die Ochsen. Er kaufte noch 28 Stück.

den 28. Maj liefert ich Ochsen in Toldstedt.

(len 29. betalt ich die Marieg(elder) an Herr Knudt. ') Peter Schlachter kriegt die letzten Ochsen, den 13. og 14. Juni von (er Brücke.") Ich krieg eine Obligation von P. S. auf $200 \mathrm{Rd}$.

den 28. Juni fingen wir an Gras zu mähen in Nørkjær.

den 29. war ich in Østergaardsmühle bei meinem Bruder Peter, er hatte Brief von meinem Bruder Hans aus Holland. Er will will Gott es nach Riga.

den 5. Juli war unser König hier auf dem Schlosse, ich war auch da. Mett war mit zur Stadt.

den 13. Juli harkten wir Heu in Egberg, ich war zur Stadt. Wir haben 40 Futter ${ }^{3}$ ) Heu.

den 23. war Jes to $\mathrm{Hau}^{4}$ ) bei der Kirche.

den 23. var Nicolay Serdien hier und seine Frau und wechselt Geld mit mir. Wir haben noch 14 Fuder Heu aus. Wir kriegten Brief von unseren Hans. Gott sei Lob und Dank.

den 5. Aug. kriegen wir deu Rest von unser Heu ein. Dieses Jahr haben wir 89 Fuder.

den 13. Aug. kam eine Kiste Thee von meinem Bruder Hans Paulsen.

den 16. holte ich ein Fuder Blei zu der Kirche.

den 15. heuerte ich Martin für 11 Rd. und 2 Hemde.

den 19. Aug. machen wir ein Dieg(! $\left.)^{5}\right)$ in Nørkjær.

1) Pastor Knud Hybschmann, født i Osterløgum, var Diaconus i Lajt $1707-1760$.

2) Drengesgaard kaldtes før "w Bro«. Paa Meiers hort over Aabenraa Amt fra 1641 "die Brückeর.

3) Fuder.

4) til Hovarbejde, Spandtjeneste for Kirken.

5) et Dige. 
den 2i. lieferte ich mein Bruder Peter 50 Mark zu der La(lung. $\left.{ }^{1}\right)$

den 27. war ich in Apenrade bei Büchsenmacher $u$. krieg 2 Pistolen.

den 9. September war ich zu Klippleff Market ${ }^{2}$ ) verkaufte nichts.

den 20. kriegen wir unser Korn ein. - Gott sei Lob u. Dank! den 26. war Amtsverwalters Frau hier $u$. macht Käse für Bürgermeister.

1. Oktober liefert ich 2 Ochsen an Bürgermeister a St. 16 Rd. den 7. October haben wir schon Schnee, Frost u. Winter. den 9. kauft ich ein Bull.

den 14. war Herr Pastor Lorenz Fabricius und der Pastor von Burkall u. bekommt 1 Tonne Apfel für $1 \mathrm{Rd}^{{ }^{3}}$ )

den 27. war ich zu Kost ${ }^{4}$ ) bei Jes Mortensen in Nørby. den 28. war ich zu Bruttbett") bei Hans Madsen Krag il Blosholm.

den 1. Nov. kam mein Bruder Hans P. mit seinem Schiffe nach Hadersleben - Gott sei Lob u. Dank.

den 11. schlachten wir drei Schweine.

den 1. Dec. heuerte ich Svenne Jepsen Maag, er soll will Gott es nach Frankreich.")

den 13. war ich u. Svenne zur Stadt mit 2 Seiten Speck für LPfd. 3 Mark, und eine Balle Butter für 7 Mk. 8 Sk. u. Bürgermeister krieg ein Schinken a Pfd. 4 Sk. Casper Schmidt war hier bei unser Klock.

den 18. Dec. kam das letzte Vieh ein. Dieses Jahr haben wil 21 Stück Vieh u. 10 Pferde. Gott gab uns Glück u. Segen.

1) formodentlig Andel i en Skibsladning.

2) Altsaa allerede i 1740 var Kliplev Marked den 9. Sept.

3) L. Fabricius var Pastor prinı. i Lajt 1725-1753. IIan er kendt som en betydelig Orientalist. Præsten fra Burkal, som kabte Fbler i Barsmark er Andreas Ambders. Sp. i Burkal 1725-19.

) Bryllup.

5) Brudeseng, fejredes inden Brylluppet.

6) Formodentlig en Sømand. 
den 28. war ich zur Stadt mit B. M. ('eld ${ }^{1}$ ) und für mein Schwiegervater Marquardt Bossen.

Anno d. 1741.

Gott gieb uns ein glückliches Neu Jahr.

den 4. Jan. haben wir de weste Hild ledig. De andre ist ganz voll.

den 5. war ich u. Jep Copperholdt mit 207 M. to Peter Caspersen. Die B. M. Gelder stehen in der Ostsee für 12 pro Cent u. in der Nordsee für 14 pro Cent. Unser Matz kriegt Hyr bei Peter Caspersen.

de 19. Jan. waren wir Volmächtigen citiert um Fadenholz") welches nach Copenh. soll.

den 20. hauen vir alle Piele ${ }^{3}$ weg beim Damn.

den 28. hauen wir ein Bøg in Süderholt zu Planken (!)

den 1(i. Febr. gjæren wir in der Rørskøvt. $\left.{ }^{4}\right)$

den 1. Märts segelt Svenne J. Maag von Apenrade u. will nach Frankreich - Gott gieb ihm Glück u. Segen! Ich gab 23 Mark zu Asmus Iversen von Eschels Schiff.

den 14. liefert ich 100 Rd. zu Barthold Serdien. Gott gab mir Glüık!

den 21. war ich beim Amitmann um abzumachen wie viel das Magazin Heu u. Stroh kosten soll. Heu kostet pr. Fuder $2^{1 / 2}$ Rd. Stroh 2 Mark.

den 10. April 1741 kommt unsere Tochter Bodil zu schule. Gott gieb Glück dazu.

dell 15. war ich zu Beichte, auch zur stadt.

den 21. liess ich mich aderlassen, ich wurde etwas krank.

den 24. war der Pastor Herr Lorenz Fabricius hier bei unsern Vater.

dell 2. Maj war ich in Apenrade u. betalt B. Serdien 26 Mark

1) muligvis Penge i Skibsaktier. Pastor Thade Petersen gør opmærksom paa, at »B. M. Gell« muligvis er Bodmerilaan, en Slags gammeldags Søforsikring. At Rentefoden er højere $i$ Vesterhavet end i Østersuen, kunde tyde paa det.

2) Favntræ.

3) Piletræer ved Dammen.

1 satte vi Gjærde i Rørskifte, Skifte, sønderj. Skøvt. 
14 Sk. für Umkosten für mein Pait in Jacob Serdiens Schiff.

- Gott gieb Glück dazu.

den 16. Maj jagen wir unsere Ochsen aufs Gras. Es ist hart Winter gewesen, nun ist etwas besser. Wir jagen unsere Schafe auf die Heide beim Roten $\mathrm{Krug}^{1}$ ) 7 Alte, 2 Lämmer.

den 6. Juni war ich u. Paul Krag in Dyrhave um Land zu messen. ${ }^{2}$ )

den 7. Juli war beide unsere Knechte zur Musterung in Tolsted.

den 20. war ich u. Mett zu Markt, wir hatten ein Ell nit zu einer Pumpe.

den 11. Aug. kauft Kammerherr Gynderot ${ }^{3}$ ) mir Jep Hansens Kuh ab.

den 15. Sept. war Herr Amtmann hier. Wir fahren den letzten Buchweizen ein. - Gott sei Lob u. Dank für den guten Sommer!

den 18. liess ich mich Aderlassen.

den 21. krieg ich 21 Ducaten von Serdiens Schiff.

den 2. Oktober kamen die Dragonen.

den 3. maschieren sie wieder ab.

den 2. war ich u. Mett zur Beichte.

den 2. kam mein Bruder Hans P. zu Hadersleben. -- Gott sei Lob u. Dank!

den 17. war der Probst ${ }^{4}$ ) hier.

den 2. Nov. war ich zu Kost bei Nis Petersen auf Barsø.

den 2. Dec. war der Pastor Herr Canutus ${ }^{5}$ ) hier bei Mett.

den 3. betet der Pastor Lorenz Fabricius für Mett.

den 18. Dec. kam unsere Kühe ein.

1742.

den 21. Jan. war Mett zu Kirche im Schlitten.

den 10. Febr. war Mett u. Kirsten in Vedsted Kirche.

1) paa Lunderup Hede ved Røde Kro.

2) Udskiftningen begyndte altsaa tidlig i Løjt Sogn. Der er i disse Aar ofte Tale om Opmaalinger.

3) Amtmand von Günderoth.

4) Dr. Koch i Aabenraa.

5) Canutus eller Knud Hybschmann. 
den 11. to Bassel in Blosholm.

den 18. Marts war ich u. Mett in Hadersleben, ich krieg 200 Mark bei (!) meinem Bruder Hans P. Der Oberstleutnant heuerte Nis Hansens Dammn ${ }^{1}$ ich soll selbst die Nachgrö) haben.

8. April segelt I. Serdien nach Irland.

den 30. April war Herr Pastor Knud Hybschmann bei unserem Vater.

den 1. Maj war ich in Apenrade auf Kapitän Eschel Jensens Schiff. Gott gieb Glück.

den 6. Maj krieg ich 400 Mark von Herr Pastor Lorenz Fabricius.

den 13. Mai betet der Pastor für unsere Tochter Ellen, sie ist sehr krank.

den 15. bekommt mein Schwager 57 Mark. Er hat auch Part in Hans Paulsens Schiff.

den 20. Mai war ich und Mett zum hl. Abendmahl.

den 21. war ich bei Doctor Fast für unsere Tochter Ellen. den 23. war ich mit ein Fuder Bark zu Peter Tondering.") den 28. Maj starb unsere kleine Tochter Ellen Paulsen des Morgens $1 \frac{1 / 2}{}$ Uhr.

den 29. war ich bei dem Pastor Lorenz Fabricius und liess die Leichenpredigt ${ }^{5}$ ) schreiben. Herr Pastor Lorenz kriegt 7 Mark u. Herr Pastor Knud kriegt 10 Mark.

den 30. war ich u. meine Schwiegerin Maren Bossen in A. u. kaufte allerlei für Ellens Beerdigung.

den 3. Juni wurde unsere Tochter Ellen Paulsen beerdigt. Wir hatten Brief von meinem Bruder Hans Paulsen in (!) Riga. 11. Juni waren beide Knechte in Hoverslund $\left.{ }^{b}\right)$ und holten Lyng.

den 15. Juni verkauft ich ein zweijähriges Pferd für $35 \mathrm{Kd}$. den 6. Juli passierte mein Bruder Hans P. den sund.

1) Et Engdrag.

2) Eftergrøden.

4) Fn ganmel Garverfamilie i Aabenraa, helt op til Nutiden.

5) Ligpradikenen opbevaredes siden i Hjemmet.

1) Hovslund, i aldre Tid Hoverslund. 
den 21. Juli war ich u. Mett in Flensburg. Ich verkaufte 3 Balle Butter u. krieg 5 L. $^{1}$ ) Stockfisch. Verkaufte Leinen, 87 Ellen a E1l. 4 Sk.

den 11. August biss der Wolff $\left.f^{2}\right) 3$ von unseren Schafen.

den 22. kam der Schulmeister hier op de Kost. Brief von meinem Bruder aus Liverpool.

den 12. Sept. war ich zu Kirche u. dankte Grott für einen guten Sommer.

den 13. Sept. war ich beim Amtmann fưr Jes Bröde mich erkundigen wie viele Bäume ${ }^{3}$ ) er pflanzen sollte.

den 24. Sept. 1742 des Morgens 6 Uhr u. 55 Minutten wurde unser Sohn Hans Paulsen geboren.

Auf St. Michaelis den 29. Sept. wurde Hans Paulsen getauft.

den 30. Sept. hatten wir Kinderbier.

den 27. Oktober kommt Eschel Jensen zu (!) Hause mit seinem neuen Schiff. Gott sei Lob u. Dank.

den 4. Nov. hielt Mett. ihren Kirchengang.

den 9. brannten wir Branntwein.

den 23. var ich zur Allmannting.

den 29. kauft ich 3 Bücher von Jørgen Elberg für 3 Cadus Tobak. Der Propst var in unsere Kirche.

\section{Anno d. 1743.}

den 17. war mein Bruder Hans Paulsen hier u. kriegt sein Taufattest bei Pastor Lorenz Fabricius.

den 24. holt ich ein grosser Koffert, kostet $10 \mathrm{Rd}$. u. ein kleiner kostet 11 Mark.

den 26. Febr. war ich Dinghörer.

den 22. resten vir das kleine Haus auf Egbjerg.") Hellet.

1) Lispund.

2) Den sidste Ulv i Løjt Sogn blev skudt 1780 ved Hørroy vel

$\left.{ }^{3}\right)$ Det var paabudt nygifte at plante et vist Antal Treer ved Ejendommen. Præsten skulde afkræve Brudeparret Attest for at dette var sket. Se Falck, S. H. Privatrecht IV. B. pag. 334. Forordningen (27. April 1737) gjaldt kun for Skovegnene, dog synes den ogsaa at være bleven overholdt i Midtslesvig. Forordningen blev ophævet 1782. Se ogsaa C. F. Callisiens Anleitung 1834 p. 159 .

4) Et saadant blev afbrendt i 1848 af Soldaterne. 
den 16. April kauft ich 40 Buchen in Kragbæk in J. Hansells Lücke') für 20 Mark u. 1 Rolle Tobak.

den 22. Mai wurde für (!) mich 50 Mark Leinen gestohlen. Der Amtmann befohl, dass wir Barsmark durchsuchen sollte.

den 14. Juni war ich beim Amtmann wegen die Kirkebyer Schulmeister.

den 1. Juli wurde Hans M. ${ }^{2}$ ) Schulmeister in Kirkebye.

den 17. verkauft ich 4 Ochsen zu Hansen in Christian Alberts Kau. ${ }^{3}$ ) Ich hatte Brief von meinem Bruder Hans Paulsen aus Norwegen, dass er klar war in Drammen.

den 4. Sept. kamen Soldaten vorbei von Fühnen.

den 1. Okt. war ich bei Prediger Herr Lorenz Fabricius wegen Vermögen Steuer. Ich muss 380 Mark bezahlen.

den 6. war ich u. Mett zum Abendmahl.

den 26. Oktober betet der Prediger Herr Lorenz Fabricius für unseren Vater.

den 29. Oktober um $12 \mathrm{Uhr}$ stirbt unser Vater Hans Paulsen. Er war 83 Jahre alt.

den 31. Oktober war ich bei den Prediger Herr Lorenz Fabricius u. Herr Knud Hybschmann. Herr Lorenz krieg 23 Mark u. Herr Knud 9. Ich u. Mett waren auch zu Stadt u. kauften ein Anker Wein 9 Mark, Gewürz 9 Mark, Smygels 3 Mark u. Hand(giffe') 3 Mark.

den 1. Nov. liesen wir beten für unseren seeligen Vater.

den 2. November legten wir unser Vater in den Sarg.

den 3. Nov. wurde Vater beerdigt. Die Schulmeister gab ich :3 Mark. Da waren 3 Jungen mit ${ }^{5}$ ) die gab ich 3 Sk. unser Schulmeister gab ich 1 Mark und Peter Snedker 2 Mark.

den 20. war Maren Kasses ${ }^{\theta}$ ) hier, Sie kauft eine Quie für 's Rd. Sie liat bezahlt.

1) En lyk = et Stykke indhegnet Jorl.

2) Hans Mikkelsen, Degn og Skolelærer i Løjtkirkeby. Kendt som liegnemester og Visemager. Se Sønderj. Maanedsskrift 4. Aarg. S. 129.

3) Koog, urltales endinu paa sønderjydsk Kou.

4) 'Til Ligkisten.

5) Til at synge sammen med Degnen.

") I Barsmark holder en Vej endnu "Iaren kasses Foerte. 
H. Hejselbjerg Paulsen.

den 25. lieferten wir Gerste u. Brot zu Herr Loren\% u. Herr Knud. $\left.{ }^{1}\right)$

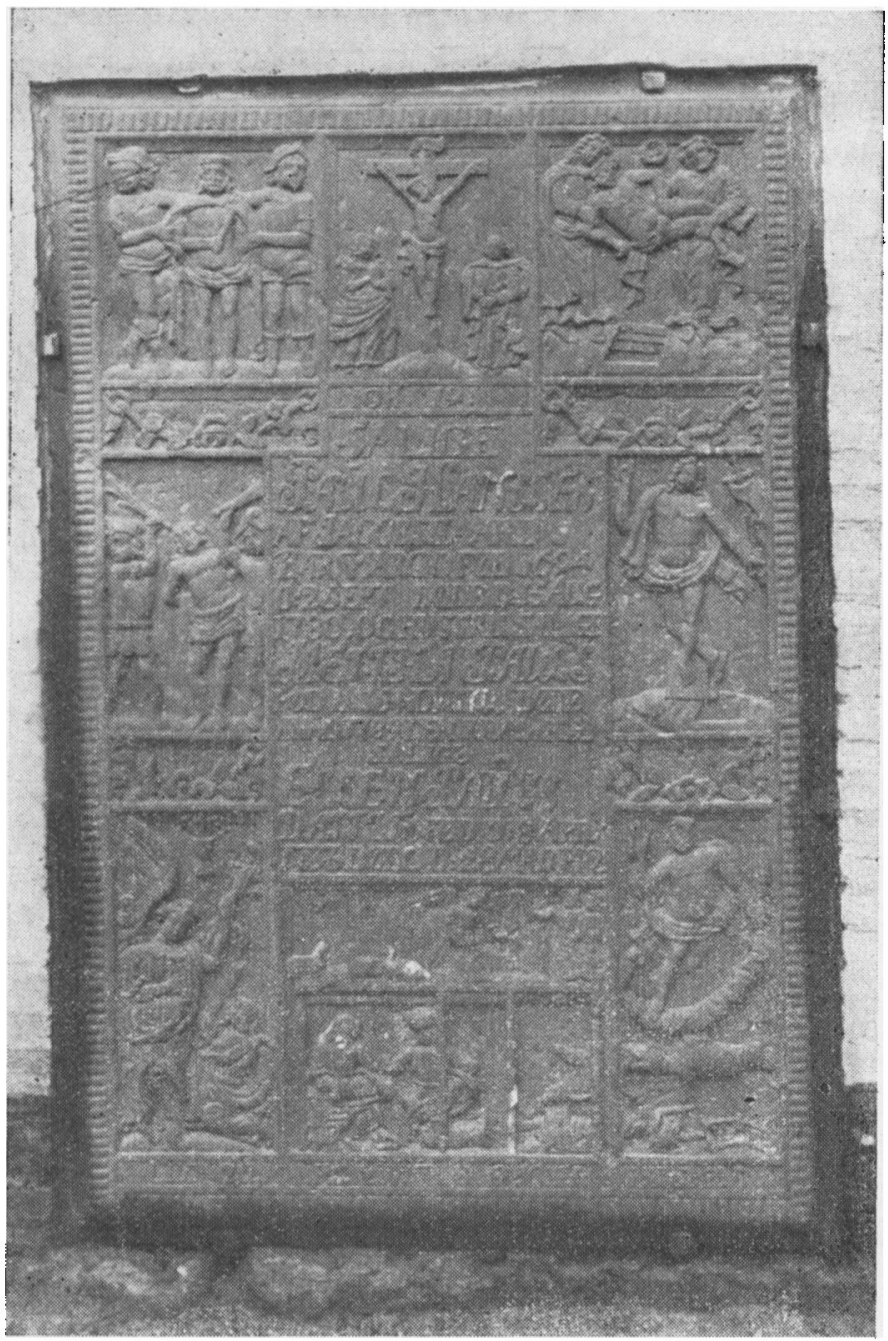

Ligstenen over Paul Hansen sidder nu indmuret $i$ hans gamle Gaard Jacobsgaard i Barsmark. Stenen er ca. $1,75 \mathrm{~m}$ høj. Indskriften og de 8 udhugne Billeder i Relief ses endnu meget tydeligt.

1) Prasteme, formodentlig Tiende. 
Indskriften or fulgende:

\author{
Salige \\ PAUL HANSSEN \\ af Jacobsgaard $i$ \\ Barsmark, fød 1694 \\ d. 2 Sept. døde d. 15 Aug. \\ 1780. og Hustru salige \\ MET'THA PAULS \\ fød d. 15 Nuv. 1712 døde \\ Anno 1789 den 11 Martz. \\ Salige \\ ELLEN PAULS \\ DATTER fød d. 8 April \\ 1733 døde d. 28 Maj 1742.
}

Udenom selve Indskriften er indhugget 8 ca. $50 \mathrm{~cm}$ høje Billeder af Jesu Livs Historie.

Nederst ses et dobbelt Billede, Jesu Fødsel, med Henvisning til Luc. 2 V. 7. 8. 9. 10. 11.

Nederst til venstre: Jesu Sjælekamp i Gethsemane, Luc. 22.

Ovenover det: Jesu Hudstrygelse, Joh. 19.

Gverst til venstre: Ecco homo. "Se hvilket Menneske",

Midterste Billede: Jesus paa Korset, Joh. 19.

ftverst til Højre: (iravlægningen, Luc. 23.

Neden under: Jesu Opstandelse, Luc. 24.

Nederst til Højre: Jesu Himmelfart, Luc. 24.

den 17. Dec. kanı unser Vieh ein.

den 23. Dec. war ich u. Mett zu stadt mit en Sid Speck.

Anno d. 1744.

Gott gieb uns ein gutes Neu Jahr! Amen. Gott sei Lob u. Dank für das alte Jahr!

den 16. Jan. war der Jägermeister u. Jägerbursche hier. Wir haben 8 Bette für fremde Leute.

dell 6. Febr. war ich u. die Creditoren auf dem Rathhause wegen Curtzweils Haus.

den 17. war Auktion auf Kurtzweils Haus. B, Serdien kriegt es für $1215 \mathrm{M}$.

den 19. April war ich und Mett zum heiligen Abendmahl.

den 4. Mai messe ich in Dybvighoved.

den 16. Mai war ich beim Hausvogt um ein neues Schulhaus in Barsmark zu bauen. 
den 19. Maj hyrt ich Hans P. für 11 Rd. 1 Pfund Wolle, Leiuen zu ein paar Büchse.

den 24. hyrt ich J. M. für 23 Mark, 2 Hemde, u. Leinen. den 12. Aug. fangen wir an mit dem Roggen. Maren Kasses kriegt ein Ferkel u. ich ein L.-Pfund Hopfen. 